\title{
Clinical Outcome of Cervical Key-Hole Foraminotomy for Monolevel Cervical Radiculopathy
}

\author{
Samy Moussa Selim \\ Department of Neurosurgery, Faculty of Medicine for Girls, Al-Azhar University, Cairo, Egypt \\ Corresponding auther: Samy Moussa Selim, E-mail: samy_seliem@yahoo.com, phone: 00966509776812, 00201113319187
}

\begin{abstract}
Background: Cervical degenerative disc disease is the most common cause of acquired disability in patients over the age of 50. C6-C7 and C5-C6 are the most common levels involved in it. Radiculopathy can be unilateral or bilateral and single level or multiple levels.

Objective: To know about the clinical outcome of cervical key-hole foraminotomy for monolevel radiculopathy.

Materials and methods: This cross sectional study was conducted in neurosurgery department, $\mathrm{Al}$ Qunfudah General Hospital, Saudi Arabia from January 2017 to December 2017. All admitted patients with mono level cervical radiculopathy due to posterolateral prolapsed intervertebral disc (PIVD) or bone spur who undergone key hole foraminotomy were included in this study, while patients with severe cervical degenerative diseases, myelopathy, instability, trauma, infection, tumors of cervical spine were excluded. Patients age, gender, level of cervical spine radiculopathy, pre-operative signs and symptoms, Pre and post-operative complications with post-operative variation in clinical status were recorded on a designed proforma. Minimum 1 month follow up was done.

Results: Total 20 patients were included in which there were $12(60 \%)$ male and $8(40 \%)$ female with mean age 45 years (32-65 yrs.). The mean duration of complaint was 11 months (6-17 months). In all of these cases C6, C7 level involvement was the most common with total $8(40 \%)$ patients. Complete recovery was found in $18(90 \%)$ patients and partial in $2(10 \%)$ patients while there was unintended durotomy in $1(5 \%)$.

Conclusion: Minimally invasive posterior cervical foraminotomy for cervical radiculopathy is an effective option in well selected patients in postero-lateral foraminal stenosis due to prolapsed intervertebral disc and osteophytes formation.
\end{abstract}

Keywords: Cervical foraminotomy, Clinical outcome, Monolevel cervical radiculopathy.

\section{Introduction}

Cervical radiculopathy is a condition which is caused by compression or irritation of cervical nerve root by soft cervical disc or bone spurring from spondylosis. When the size of the cervical neural which formina reduces then it causes the inflammation of cervical nerve root. Clinically it presents in the form of neck pain, upper limb pain, motor or sensory loss in upper limbs depending upon the level of cervical root effected. The population which most commonly effect from it is middle and old age $(1,2)$. Cervical degenerative disc disease is the most common cause of acquired disability in patients over the age of 50 ${ }^{(3)}$. C6-C7 and C5-C6 are the most common levels involved in it. Radiculopathy can be unilateral or bilateral and single level or multiple levels. Since cervical disc herniation is more common than the spur compressing upon the cervical root therefore in clinical practice most of the patients gives the scenario that there are symptoms to me on getting up in the morning without any identifiable stress or trauma ${ }^{(3,4)}$.

History and physical examination are considered the main pillars while making the diagnosis of cervical radiculopathy. Spurling test, upper limb tension test, cervical distraction test and ipsilateral cervical rotation reduction more than 60 degrees increases the likelihood of cervical radiculopathy if these test are positive. If all tests are positive, then the positive likelihood ratio (LR+) for diagnosis of cervical radiculopathy will 30 . It decreases to 6 when 3 of 4 tests are positive. Based on these values a $\mathrm{LR}+$ superior to 10 is considered large, and between 5 and 10 moderate; thus, it increases the possibility that the impairment in question is present. If we combine these clinical tests with history of patients then the diagnosis of cervical radiculopathy can be made more accurately ${ }^{(5,6)}$. Along with clinical diagnosis many diagnostic tests are available to confirm 
the diagnosis of cervical radiculopathy which includes $x$ ray of cervical spine, CT, MRI of cervical spine and electrophysiological studies in the form of EMG in which $\mathrm{X}$ Ray gives information about boney changes and curvature.

CT myelography provides more information about the bones anatomy as compared to simple $\mathrm{X}$ ray of cervical spine in addition to myelography which can show us the space occupying lesion compressing on corresponding nerve roots. In all diagnostic tests MRI of cervical spine is the investigation of choice because it gives more precise information about the soft tissues of cervical spine like intervertebral disc, ligaments, spinal cord and nerve roots. EMG examination is primarily used in patients with questionable neurologic involvement to rule out other peripheral neuropathic disorders, to assess axonal recovery, and to assess whether an anatomic abnormality observed on imaging is correlated with neurologic injury $(7,8,9,10,11,12)$.

Depending upon patients clinical and radiological status either conservative or surgical approach is used for treatment of cervical radiculopathy. Majority of the patients gives a very god response to conservative therapy in the form of analgesics, cervical collar and physiotherapy. When the conservative treatment fails then the next option is to do the surgical intervention to the patients. Anterior cervical discectomy with fusion and posterior cervical foraminotomy are the options available for surgical treatment of patients. Posterior cervical foraminotomy has several advantages over anterior cervical discectomy such as preservation of cervical motion, no need for internal or external bracing, and eliminates the risk of swallowing or voice-related complications postoperatively $(13,14,15,16)$.

Rational: cervical radiculopathy is common in our setup because majority of the population is uneducated especially females which carry loads on their head in their day to day life activities causing repeated trauma to cervical spine. Doing this study in our setup will open a window for future research on this topic. Furthermore, by comparison with international studies will show us the deficiencies of our techniques and this will be a step to improve our knowledge and techniques for the patient's betterment.

Materials and Methods
This prospective study included a total of 20 consecutive patients with mono-cervical radiculopathy due to posterolateral cervical intervertebral disc and bony spur attending at Neurosurgical Department, Al Qunfudah General Hospital, Saudi Arabia. Approval of the ethical committee "Postgraduate Medical Institute, Inistitutional Research and Ethics board" and a written informed consent from all the subjects were obtained. This study was conducted between January 2017 till December 2017.

Exclusion criteria:

Patients with severe degenerative spine disease, previous cervical surgery, instability, trauma, infection, tumour and associated major comorbidity.

All patients were operated upon by posterior cervical key hole foraminotomy and the total duration of follow up was at least 1 month after the surgery. Data was collected on a designed proforma from radiology and operative records and different outcome measures. Data was collected on a designed proforma from radiology and operative records and different outcome measures. Data was analyzed by entering it into statistical software SPSS version 20 and was expressed in percentages and was presented in different charts, tables and graphs. All patients were reviewed by age, sex, diagnosis, duration of complaints, and clinically examined for neck pain and brachialgia, muscle power grading including (shoulder abduction, adduction, Elbow extension, flexion Wrist extension, flexion, Finger adduction, abduction), In reflexes Triceps, Biceps and Brachioradialis and sensory deficit. All patients were assessed by radiology like X-Ray, MRI (Fig no $1 \& 2$ ), CT, and EMG when needed) demonstrating lateral foraminal disc herniation or foraminal stenosis by osteophyte. Before surgical intervention patients were subjected to pre-operative preparation, and investigated for complete blood count $(\mathrm{CBC})$ and viral serology (HbsAg and Anti-HCV $\mathrm{Ab}$ ) was done. Blood and surgical instruments were arranged according the need of the surgery. An informed consent was taken, explaining the prognosis. The ethical approval was taken from the hospital ethical committee, "Postgraduate Medical Institute, Institutional Research and Ethics board". Then post-operative clinical outcome of cervical keyhole foraminotomy for monolevel radiculopathy was revived. 


\section{RESULTS}

Total 20 patients were included in which there were $12(60 \%)$ male and $8(40 \%)$ female (Fig no 1). Patients mean age was 45 years (32-65 yrs.). The mean duration of complaint was 11 months (6-17 months) in which $4(20 \%)$ patients were in $3^{\text {rd }}$ decade, 9 $(45 \%)$ in $4^{\text {th }}$ decade and $7(35 \%)$ patients were in $\geq 5$ decades (Fig no 2). Among 20 patients the most common was $\mathrm{C} 6$ radiculopathy having $8(40 \%)$ followed by C5 having $6(30 \%)$ while $6(30 \%)$ patients had C7, C8 radiculopathy (Fig no 3). Visual analogue scale is used for assessment of cervical radicular pain (Table no 1). Intra-operative complication and Postoperative clinical outcome was summarized up till 1 month we found that $18(90 \%)$ recovered completely while $2(10 \%)$ showed partial recovery from pain and in $1(5 \%)$ patient there was unintended durotomy (Fig no 4).

Figure 5 and 6 showing MRI study for patient presented by C6-C7 left foraminal disc and patient had left $\mathrm{C} 7$ radiculopathy.
Table no 1; Visual analogue scale for assessment of cervical radicular pain

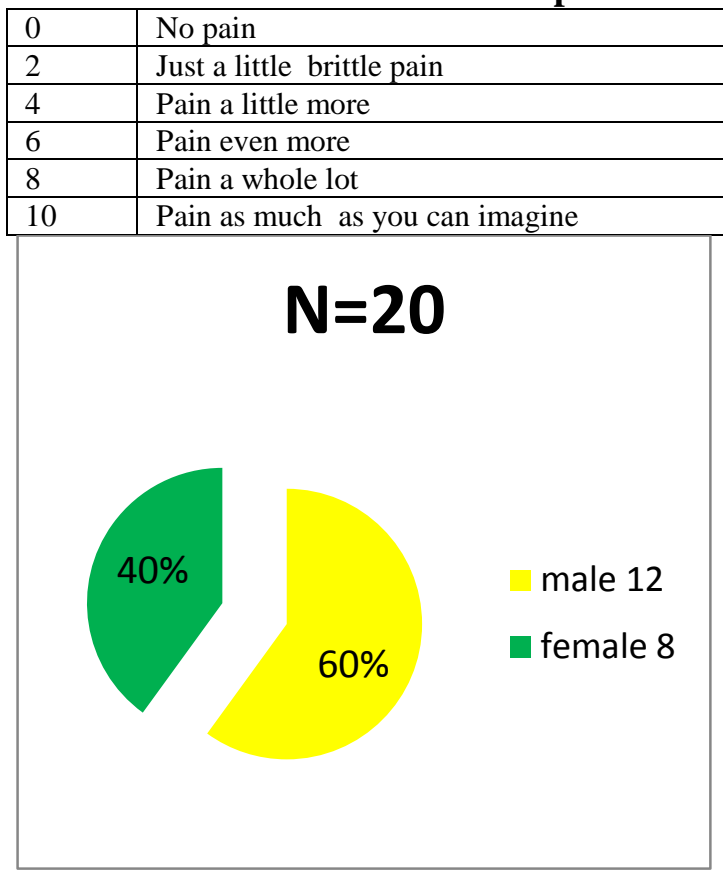

Fig no 1: Gender wise distribution of patients $\mathrm{N}=20$

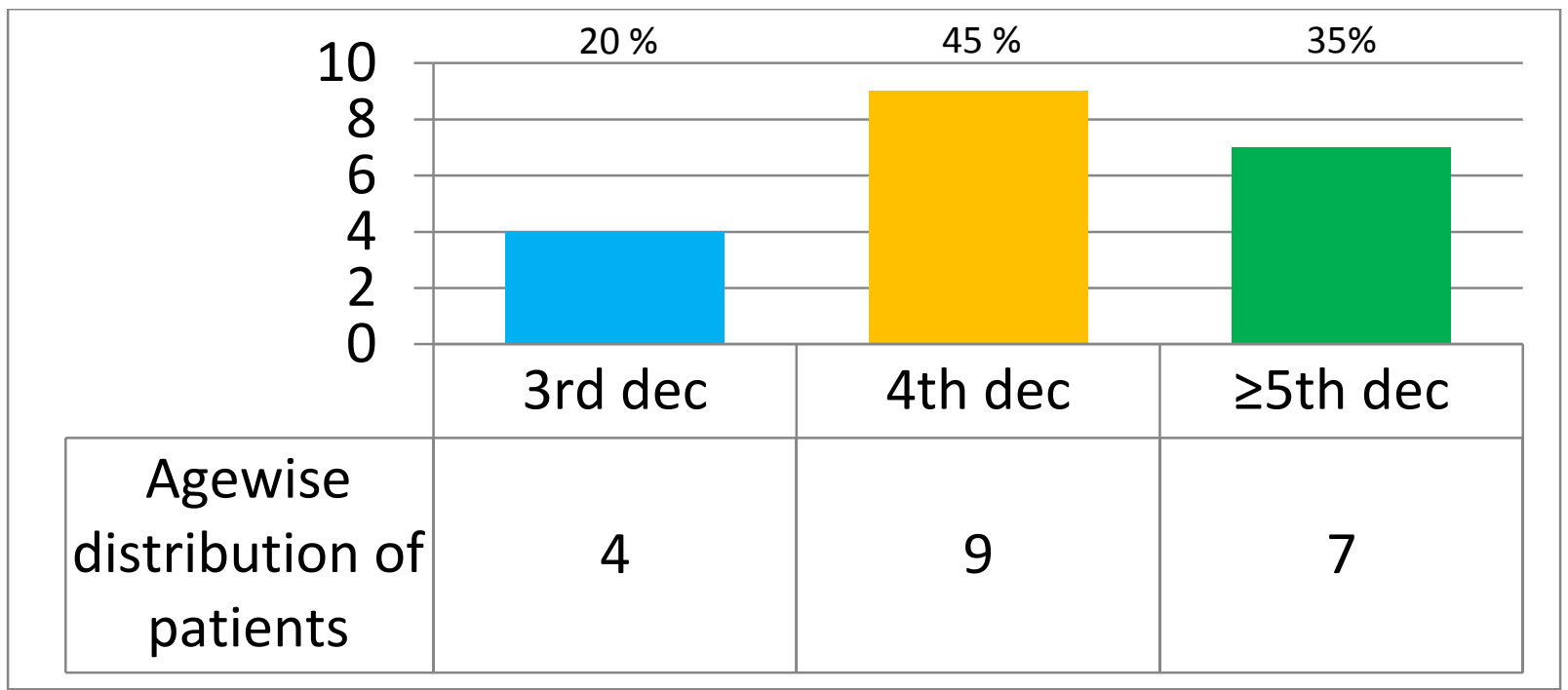

Fig no 2: Age wise distribution of patients $\mathrm{N}=20$ 


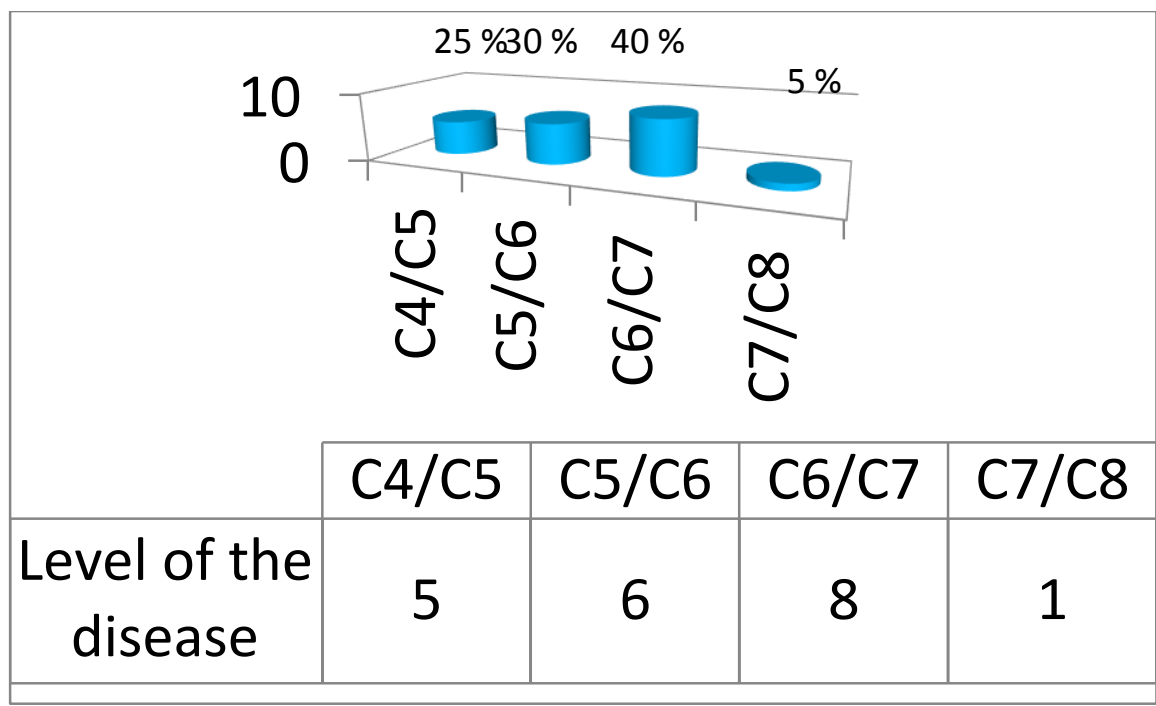

Fig no 3: Level of cervical radiculopathy $\mathrm{N}=20$

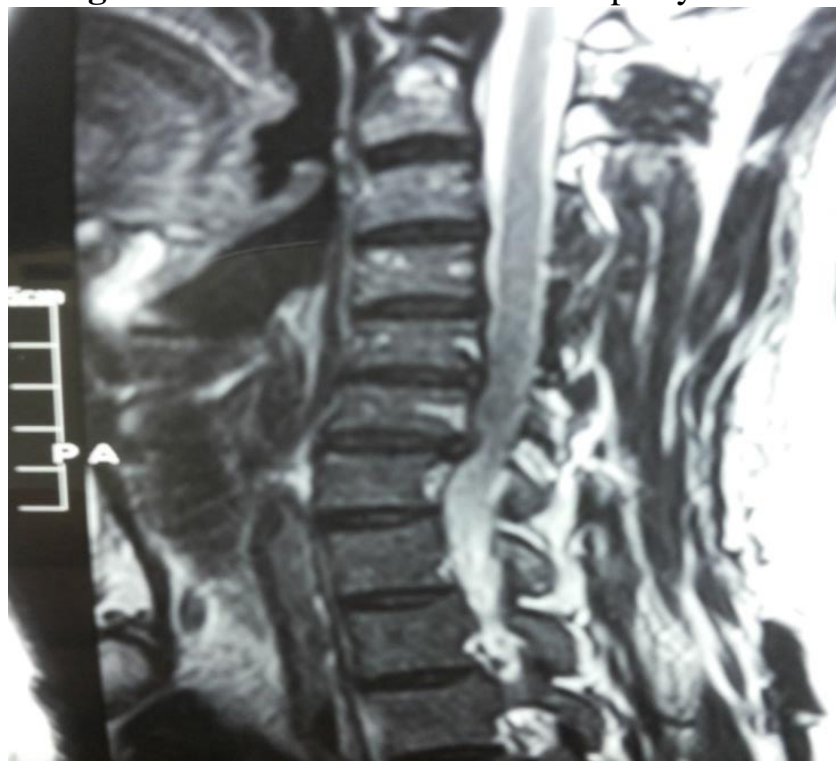

Fig no 4: clinical outcome of key hole foraminotomy for mono level cervical radiculopathy $N=20$

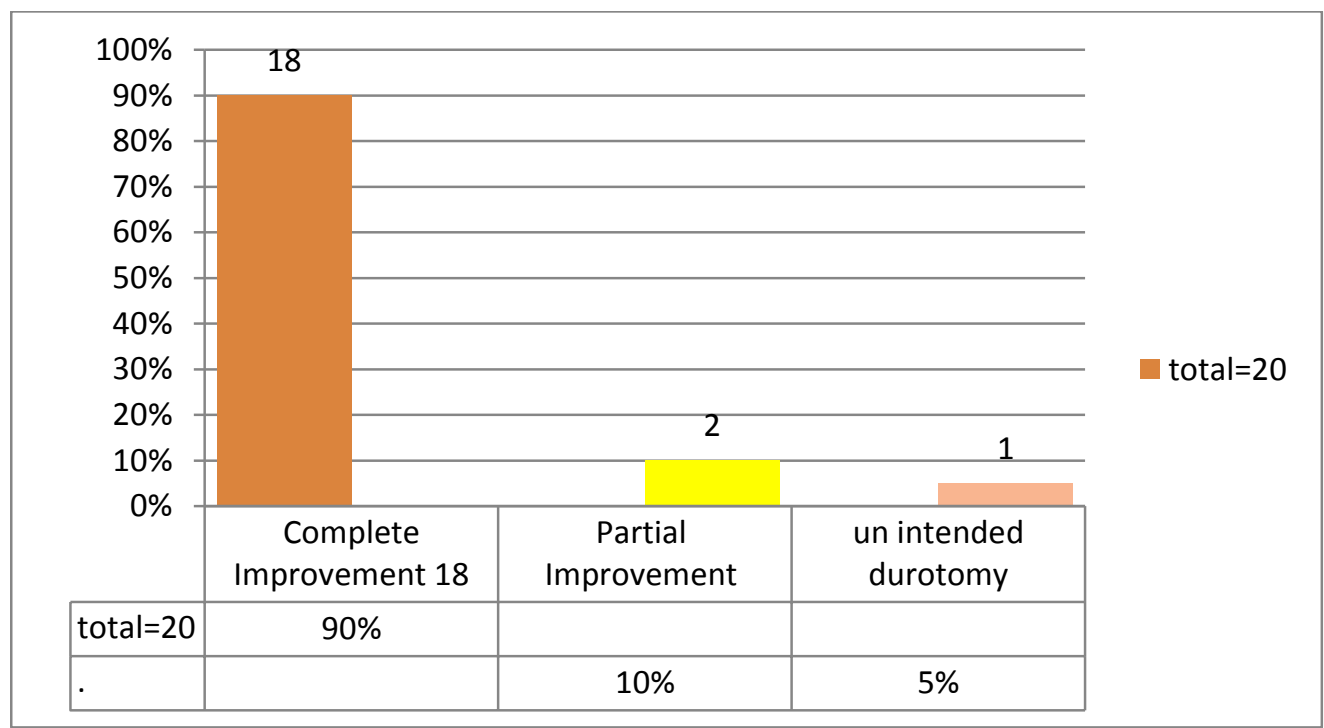

Fig no 5: MRI of cervical spine sagittal/parasagittal view showing reversal of normal cervical lordotic curve and PIVD at the level of the C6 and C7 


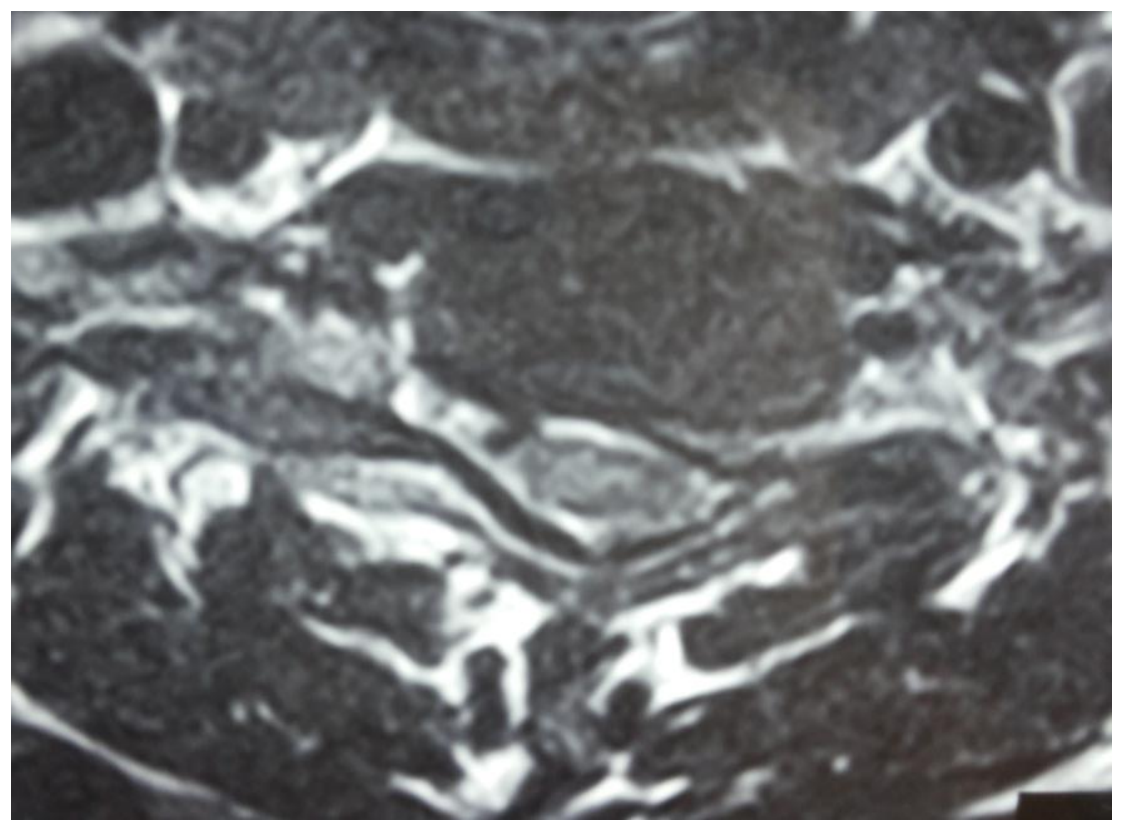

Fig no 6: MRI of cervical spine with axial view of a patient presented with cervical radiculopathy shows PIVD at the Left dorsolateral aspect and compressing nerve root

\section{Discussion}

Mixter and Barr for the first time introduced posterior approach for the treatment of cervical spinal cord pathologies then followed by Scoville, Epstein, and Fager. Ducker contributed for keyhole foraminotomy in literature. Keyhole foraminotomy are the terms used to describe those posterior cervical approaches in which removal of foraminal or posterolateral cervical discs and boney spurs are removed. This procedure can be performed either unilaterally or bilaterally either at one or two levels depending the condition of patients. For obtaining good results it is extremely important that patients should be selected properly pre operatively with additional good microsurgical techniques applied during the surgery $(17,18,19,20)$.

In our series males were pre dominant than females having ratio of $3 ; 2$ and most of the patients were in $3^{\text {rd }}$ and $4^{\text {th }}$ decades having frequency of $13(65 \%)$. Regarding level of involvement out of 20 cases $11(70 \%)$ cases were due to $\mathrm{C} 5-\mathrm{C} 6$ and $\mathrm{C} 6-\mathrm{C} 7$ levels and the most common level of involvement was C6-C7 with total number of cases $6(40 \%)$. According Moussa WM ${ }^{(21)}$ in his study showed that males are effected more than females having ratio of 2.3:1 and the most common age of presentation in their study was $3^{\text {rd }}$ and $4^{\text {th }}$ decades having 9 $(90 \%)$ cases out of 10 . Furthermore, according to his study $7(70 \%)$ out 10 patients had pathology at C5-C6 and C6-C7 level which shows resemblance to our series.

According to Cheng JC and colleagues $^{(22)}$ the most common levels affected were C5-C6 \& C6-C7 having 45 (82\%) cases out of 55. Other international studies have also showed that C5-C6 and C6- C7 levels are most commonly effected ${ }^{(23,24)}$. Kwon $\mathbf{Y j}^{(25)}$ in his study has showed that C6-C7 18 (50\%) was the most common level which is in accordance to our study.

Regarding post-operative outcome in our study total 18 (90\%) showed good outcome based on visual analogue scale in terms of pain control while remaining $2(10 \%)$ patients. incomplete recovery from the pain. total $1(5 \%)$ patient suffered from unintended durotomy during surgical procedure. When outcome was compared with international studies we found that from some studies our results were much better, while in others our results were in comparative range. In the study of Davis et al (26) the total post-operative follow up period was 15 years in $96 \%$ patients. Good or excellent outcomes were observed in $86 \%$ of patients. While Grieve et al. ${ }^{(27)}$ reported on the results of cervical foraminotomy for spondyolitic radiculopathy in 77 consecutive patients $70 \%$ of patients had complete recovery from radicular pain. Our results are better from these two studies because their total number of 
patients and mean follow up time was much longer than our series.

In 1997 Tomaras and colleagues (28) reported their retrospective case series on the use of laminoforaminotomy on 183 patients with cervical radiculopathy. They operated all the patients on outpatient's basis and followed the patients till 19 months post operatively. There were no immediate readmissions and the outcomes were good or excellent in $93 \%$ of patients to which are results are nearly comparable. Similarly, in other international studies the good outcome of keyhole foraminotomy is above the $90 \%{ }^{(29,30,31)}$ this smaller difference in our results and their results is mainly due to that reason that in series patients were operated by more than one surgeons while in their studies patients were operated by only one surgeon this is why our results are slightly lower than their results. In our series the total frequency of unintended durotomy was 5\% which is comparable to Terai $\boldsymbol{H}$ et $\boldsymbol{a l}$. ${ }^{(24)}$ study in which total frequency of unintended durotomy during keyhole foraminotomy was $4 \%$.

Limitations of our study are that due to low literacy rate majority of the patients are lost to follow therefore we were able to do 1 month follow up post operatively.

Conclusion: Minimally invasive posterior cervical foraminotomy for cervical radiculopathy is an effective option in well selected patients as postero-lateral foraminal stenosis in either soft disc prolapse or osteophyte for root decompression.

\section{References}

1. Persson LC, Carlsson CA, Carlsson JY (1997): Long-lasting cervical radicular pain managed with surgery, physiotherapy, or a cervical collar; A prospective, randomized study. Spine, 22(7): 751-8.

2. Radhakrishnan K, Litchy WJ, Fallon WM, Kurland LT (1994): Epidemiology of cervical radiculopathy. A populationbased study from Rochester, Minnesota, 1976 through 1990. Brain, 117( 2): 325-35.

3. Baaj AA, Uribe JS, Vale FL (2009): History of cervical disc arthroplasty. Neurosurg Focus, 10: 475-8.

4. Mayfield F H (1996): Cervical spondylosis: A comparison of the anterior and posterior approaches. Clln Neurosurg., 13: 181-8.

5. Wainner RS, Fritz JM, Irrgang JJ, Boninger ML, Delitto A, Allison S
(2003): Reliability and diagnostic accuracy of the clinical examination and patient selfreport measures for cervical radiculopathy. Spine, 28(1): 52-62.

6. Straus SE, Richardson WS, Glasziou $P$, Haynes RB (2005): evidence-based medicine. how to practice and teach EBM. Elsevier Churchill Livingstone, Toronto.

7. https://www.elsevier.com/books/electrod iagnostic.../dumitru/978-1-56053-433-4.

8. Ellenberg MR, Honet JC, Treanor WJ (1994): Cervical radiculopathy. Arch Phys Med Rehabil., 75: 342-52.

9. Lewis T, Kellegren JH (1939): Observations relating to referred pain, viscero-motor reflexes, and other associated phenomena. Clin Sci., 4: 47-71.

10. Wainner RS, Gill H (2000): Diagnosis and nonoperative management of cervical radiculopathy. J Orthop Sports Phys Ther., 30(12): 728-44.

11. Wen H, Wang X, Liao W, Kong W, Qin J, Chen X (2017): Effective range of percutaneous posterior full endoscopic paramedian cervical disc herniation discectomy and indications for patient selection. Biomed Res Int., 3610385.

12. Bhaganagare AS, Nagesh Sa, Shrihari BG, naik V, Nagarjum Mn, Pai B (2017): Management of cervical monoradiculopathy due to prolapsed intervertebral disc, an institutional experience. J craniovert Jun Spine, 8(2): 132-5.

13. Rubinstein SM, Pool JJ, van Tulder MW, Riphagen II, de Vet HC (2007): A systematic review of the diagnostic accuracy of provocative tests of the neck for diagnosing cervical radiculopathy. Eur Spine J., 16(3): 307-19.

14. Choi G, Arbatti NJ, Modi HN, Prada N, Kim JS, Kim HJ, Myung SH, Lee SH (2010): Transcorporeal tunnel approach for unilateral cervical radiculopathy: a 2-year follow-up review and results. Minim Invasive Neurosurg., 53(3): 127-31.

15. Sekhon LH, Ball JR (2005): Artificial cervical disc replacement: principles, types and techniques. Neurology India, 53(4): 445-50.

16. Bhadra AK, Raman AS, Casey AT, Crawford RJ (2009): Single-level cervical radiculopathy: clinical outcome and costeffectiveness of four techniques of anterior 
cervical discectomy and fusion and disc arthroplasty. Eur Spine J., 18(2): 232-7.

17. Zeidman SM, Ducker TB (1993): Posterior cervical laminoforaminotomy for radiculopathy: review of 172 cases. Neurosurgery, 33: $356-62$.

18. Epstein JA, Lavine LS, Aronson HA, Epstein BS (1965): Cervical spondylotic radiculopathy: the syndrome of foraminal constriction treated by foraminotomy and the removal of osteophytes. Clin Orthop Relat Res., 40: 113 - 22.

19. Witzmann A, Hejazi N, Krasznai L (2000): Posterior cervical foraminotomy. A follow-up study of 67 surgically treated patients with compressive radiculopathy. Neurosurg Rev., 23: 213 - 7.

20. Chen BH, Natarajan R, An HS, Anderson GB (2001): Comparison of biomechanical response to surgical procedures used for cervical radiculopathy: posterior keyhole foraminotomy versus anterior foraminotomy and discectomy versus anterior discectomy with fusion. $\mathbf{J}$ Spinal Disord., 14: 17-20.

21. Moussa WM (2012): Anterior cervical discectomy versus posterior keyhole foraminotomy in cervical radiculopathy. Alexandria Sci Exchange J., 48: 309-14.

22. Chang JC, Park HK, Choi SK (2011): Posterior cervical inclinatory foraminotomy for spondylotic radiculopathy preliminary. J Korean Neurosurg Soc., 49: 308-13.
23. Caglar YS, Bozkurt M, Kahilogullari G, Tuna H, Bakir A, Torun H (2007): Keyhole approach for posterior cervical discectomy: Experience on 84 Patients. Minim Invas Neurosurg., 50: 7-11.

24. Terai H, Suzuki A,ToyodaH, Yasuda H, Kaneda K, Katsutani H (2014): Tandem keyhole foraminotomy in the treatment of cervical radiculopathy: retrospective review of 35 cases. J Orthop Surg Res., 9(38): 215-20.

25. Kwon YJ (2014): Long-Term Clinical and Radiologic Outcomes of Minimally Invasive Posterior Cervical Foraminotomy. J Korean Neurosurg Soc., 56(3): 224-9.

26. Davis RA (1996): A long-term outcome study of 170 surgically treated patients with compressive cervical radiculopathy. Surg Neurol., 46: 523-33.

27. Grieve JP, Kitchen ND, Moore AJ, Marsh HT (2000): Results of posterior cervical foraminotomy for treatment of cervical spondylitic radiculopathy. $\mathrm{Br} \mathrm{J}$ Neurosurg., 14: 40-3.

28. Tomaras CR, Blacklock JB, Parker WD, Harper RL (1997): Outpatient surgical treatment of cervical radiculopathy. J Neurosurg., 87: 41-3.

29. Zeidman SM, Ducker TB (1993): Posterior cervical laminoforaminotomy for radiculopathy: review of 172 cases. Neurosurgery, 33: 356-62.

30. Kumar GR, Maurice-Williams RS, Bradford $R$ (1998): Cervical foraminotomy: an effective treatment for cervical spondylotic radiculopathy. $\mathrm{Br} \mathrm{J}$ Neurosurg., 12: 563-8.

31. Fessler RG, Khoo LT (2002): Minimally invasive cervical microendoscopic foraminotomy: an initial cliniclinical experience. Neurosurgery, 51(5): 537545. 